\title{
The effect of pitfall trap construction and preservative on catch size, species richness and species composition of ground beetles (Coleoptera: Carabidae)
}

\author{
MICHAL KNAPP and JAN RŮŽIČKA
}

\author{
Department of Ecology, Faculty of Environmental Sciences, Czech University of Life Sciences Prague, Kamýcká 129, \\ Praha 6 - Suchdol, CZ-165 21, Czech Republic; e-mail: kapon@atlas.cz
}

\begin{abstract}
Key words. Carabidae, sampling technique, pitfall trap design, bias, propylene glycol, formaldehyde, cup trap, funnel, assemblages similarity, species composition

Abstract. Pitfall trapping is the most frequently used sampling technique for epigeal arthropods. Trap design could significantly affect the catch so the results of studies using different trap designs may be difficult to compare. Although species composition is frequently investigated in ecological studies, however when pitfall trapping is employed, the effect of trap design on the recorded species composition is rarely considered. In the present study, we investigated the effect of trap construction (funnel or cup trap) and the preservative used (formaldehyde or propylene glycol) on total catch, catch of particular species, species richness and species composition of the ground beetle assemblage sampled. We were interested in the extent to which trap design could bias these characteristics. Total catch was significantly affected by trap construction and preservative used, with the effect of the latter being the stronger. Species richness was only slightly affected by trap design when assemblages caught by traps of a particular type were corrected for unequal sample size. Moreover, we show that the traps of different designs differ in their efficiency for catching particular species of carabid and thus the composition of assemblages recorded using pitfall traps is affected by trap construction and the preservative used. We conclude that to assess the full significance of the effect of pitfall trap design on the results of ecological studies on epigeal arthropods it is necessary to simultaneously use traps of various designs.
\end{abstract}

\section{INTRODUCTION}

Proper methodology is the basic prerequisite for obtaining reliable results in scientific studies (Elphick, 2008). There are a number of ways of sampling epigeal arthropods (e.g., ground beetles), but pitfall trapping is by far the most widely used. This sampling technique was used in almost $90 \%$ of the field studies on the ecology of ground beetles published in 2008-2010 and cited on the Web of Science. Pitfall trapping is popular because it is an efficient, low-cost means of sampling (Spence \& Niemelä, 1994). Although the use of pitfall traps enables researchers to collect simultaneously large numbers of specimens at several sites, which is necessary for subsequent statistical analyses, the widespread adoption of pitfall trapping as the main sampling method in studies on epigeal arthropods lacks proper methodological justification. The use of pitfall traps to sample epigeal arthropods has been criticised continuously since the 1960s (Greenslade, 1964; Adis 1979; Topping \& Sunderland, 1992; Southwood, 1994; Spence \& Niemelä, 1994; Hatten et al., 2007).

Comparisons of catches obtained using pitfall traps with those obtained by alternative sampling techniques suggest that data from pitfall traps might be biased in many ways; for example, large species are overrepresented in pitfall traps (Spence \& Niemelä, 1994; Arneberg \& Andersen, 2003), or sex ratios are markedly biased in some taxonomical groups (Topping \& Sunderland, 1992). These biases could be a consequence of the fact that pitfall trap catches reflect the activity of the specimens as well as their abundance (Thomas et al.,
2006). Therefore, the catch obtained by pitfall trapping is sometimes called "activity density" (Honěk, 1988), and, unfortunately, the correlation between activity density and real abundance can be weak in some cases (Thomas et al., 2006). However, if these biases are invariable across studies or the particular treatments being studied, a comparison among pitfall catches is relevant.

Although an un-baited pitfall trap is a simple tool, typically consisting of (i) a container buried in the soil with its rim flush with the soil surface; (ii) a preservative (absent in the case of live trapping) and (iii) a trap lid (a roof to protect against rainfall or drinking by mammals), differences in trap design could lead to additional variation in pitfall catches. That is why Adis (1979) called for a standardized trap design, but this idea has been unrealisable. Therefore, there has been considerable effort put into identifying potential sources of variability resulting from differences in trap design. Pitfall trap catches may be affected by the material the container is made of (Luff, 1975), size (Work et al., 2002), its shape (Spence \& Niemelä, 1994) and colour (Buchholz et al., 2010), the presence and type of preservative (Weeks \& McIntyre, 1997), special modifications in trap construction (Lemieux \& Lindgren, 1999), the presence of a lid (Spence \& Niemelä, 1994) and even by the experimental design (e.g., sampling interval; Schirmel et al., 2010). However, most of these studies only investigated the effect of trap design on the size of the catch and studies investigating the effect of trap design on the species composition of the catch are rare. 
Therefore, studies investigating the magnitude of the bias caused by particular trap designs for wide range of characteristics (e.g., species richness and species composition) used in ecological studies are needed. This information is essential for comparing studies that use different designs of traps and for estimating a possible effect of trap design on the results of studies where pitfall trapping is used. In the present study, we sampled ground-dwelling beetles on an abandoned field using traps of four different designs arranged in a spatial grid. The trap designs differed in trap construction (conventional cup trap and funnel trap) and the preservative used (formaldehyde and propylene glycol). This experimental design enabled us to control the effect of variability in beetle activity and environmental heterogeneity (all traps were operated simultaneously in a relatively small area; moreover, we controlled for the effect of spatial position of the traps in the grid). We assessed the effect of pitfall trap design on (i) total catch (ii) species richness and (iii) species composition. For abundant species, we further investigated the "species-specific efficiency" of particular trap designs. It is well known that species-specific behaviour may affect the catch rate of particular species (Halsall \& Wratten, 1988), and this behaviour probably interacts with trap design (Pekár, 1996). Thus, the species composition of assemblages is assumed to be affected by particular trap designs. Interestingly, although species composition is frequently measured in ecological studies, the effect of trap design on the species composition recorded (to our knowledge) has not been studied using detailed multivariate analysis (e.g., direct ordination analysis).

\section{MATERIAL AND METHODS}

\section{Field experiment}

To compare the catches of pitfall traps of various designs we performed a field experiment involving four different trap designs used simultaneously (see details in the section: pitfall trap design). Trapping was conducted in 2006 in a mediumsized (17 ha) abandoned field southwest of Prague in the Czech Republic (GPS: $50^{\circ} 02^{\prime} \mathrm{N}$; $14^{\circ} 162^{\prime} \mathrm{E}$ ). The study site was situated in the neighbourhood of the Bohemian Karst Protected Landscape Area, which is known for the occurrence there of thermophilous species and a high arthropod diversity (Tropek et al., 2010). Within this abandoned field, we selected a rather homogenous area in which we set 36 pitfall traps of four different trap designs. The nearest patch of trees was $80 \mathrm{~m}$ away. Other possible sources of habitat heterogeneity included a wetter patch of land $20 \mathrm{~m}$ to the east of the experimental area. The traps were set in a regular grid of $6 \times 6$ traps with a $12 \mathrm{~m}$ spacing (modified latin square; Fig. 1). The trap rims were carefully flushed with the soil level to facilitate the capture of even the smallest specimens. We tried to minimise disturbance of the area surrounding the traps when setting them and collecting samples. The traps were operated for four weeks in June and emptied weekly.

The samples collected were transported to the laboratory where arthropods were sorted and all carabids (Coleoptera: Carabidae) were identified by M. Knapp to species after Hůrka (1996), and the identification confirmed by P. Moravec (Litoměřice, Czech Republic).

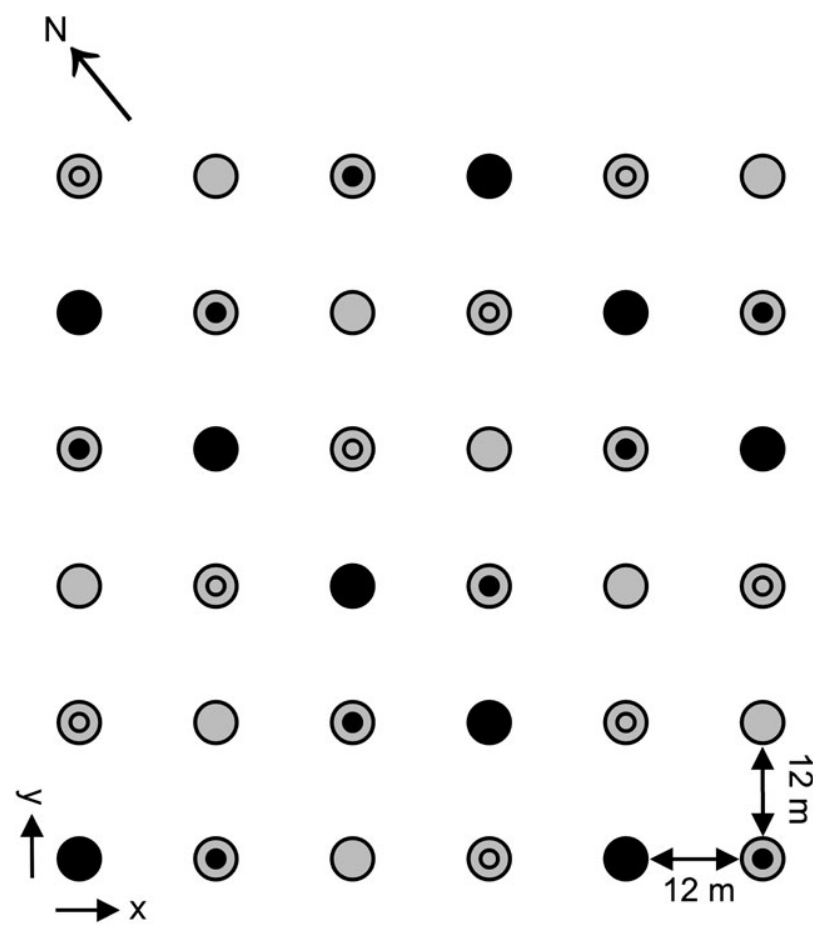

Fig. 1. Spatial configuration of the traps in the field experiment. Full symbols represent cup traps (grey - filled with propylene glycol; black - filled with formaldehyde); symbols with inner circle represent funnel traps (inner circle grey - filled with propylene glycol; inner circle black - filled with formaldehyde).

\section{Pitfall trap design}

In this study, we used four designs of pitfall traps commonly used for catching epigeal arthropods for purposes of biological surveys and ecological research in the Czech Republic (Absolon et al., 1994; Tropek et al., 2010). We employed two types of trap construction: (1) a round, conical plastic pot made from transparent polypropylene (volume 0.5 litres, $9.4 \mathrm{~cm}$ diameter and $10.2 \mathrm{~cm}$ deep) and (2) a trap made from a one-litre polyethylene bottle by cutting it in two thirds horizontally and inserting the upper part (mouth) upside-down (as the funnel) into the lower part (this makes a funnel trap with a round mouth $9.5 \mathrm{~cm}$ in diameter; for a detailed description see Absolon et al., 1994). As a preservative fluid, we used a formaldehyde solution (formaldehyde diluted with 24 parts of water) and a propylene glycol solution (propylene glycol diluted with three parts of water). These two preservatives are the most commonly used. Combinations of these factors (trap construction and preservative used) resulted in four trap designs.

All pitfall traps were covered with a roof made of $15 \times 15 \mathrm{~cm}$ transparent plexi-glass. The roof was placed $5 \mathrm{~cm}$ above the trap supported on four nails, one at each corner. Each trap was filled with $200 \mathrm{ml}$ of preservative fluid. In the cup traps, the preservative fluid was added directly into the cup, while in funnel traps, inner plastic pots were placed under the mouth of the funnel for the preservative ( $300 \mathrm{ml}$ in volume). Using inner pots in funnel traps made the manipulation of the catches more convenient. The preservative fluid was replaced weekly when the traps were emptied.

\section{Statistical analyses}

Prior to the analysis, the samples taken from the same trap were pooled over the entire trapping period (four weeks). This 
TABLE 1. Factors affecting the catch of particular species of ground beetles caught (Coleoptera: Carabidae) and the total catch of carabids.

\begin{tabular}{|c|c|c|c|c|c|c|c|c|}
\hline \multirow{2}{*}{ Species } & \multicolumn{2}{|c|}{ Preservative } & \multicolumn{2}{|c|}{ Construction } & \multirow{2}{*}{$\begin{array}{c}\text { Spatial covariates } \\
\text { used }\end{array}$} & \multirow{2}{*}{$\begin{array}{l}\mathrm{R}^{2} \text { trap } \\
\text { design }\end{array}$} & \multirow{2}{*}{$\mathrm{R}^{2}$ space $^{\S}$} & \multirow{2}{*}{ Resid. d.f. } \\
\hline & $\mathrm{Chi}^{2}$-value ${ }^{\$}$ & $\mathrm{P}$-value & $\mathrm{Chi}^{2}$-value & P-value & & & & \\
\hline Amara convexior & - & - & - & - & $\mathrm{x}, \mathrm{y}, \mathrm{x}^{2}$ & 0.00 & 0.46 & 32 \\
\hline Amara lunicollis & - & - & - & - & - & 0.00 & 0.00 & 35 \\
\hline Badister bullatus & - & - & - & - & - & 0.00 & 0.00 & 35 \\
\hline Bembidion lampros & - & - & 4.66 & 0.031 & $\mathrm{x}, \mathrm{y}, \mathrm{x}$ & 0.10 & 0.55 & 31 \\
\hline Brachinus crepitans & - & - & 9.92 & 0.002 & $\mathrm{x}, \mathrm{y}, \mathrm{x}^{2}$ & 0.13 & 0.40 & 31 \\
\hline Carabus granulatus & 6.35 & 0.017 & - & - & - & 0.21 & 0.00 & 34 \\
\hline Carabus nemoralis & 6.94 & 0.013 & 13.93 & $<0.001$ & - & 0.34 & 0.00 & 33 \\
\hline Harpalus latus & - & - & 9.89 & 0.003 & - & 0.19 & 0.00 & 34 \\
\hline Harpalus luteicornis & - & - & - & - & $\mathrm{x}, \mathrm{y}, \mathrm{x}^{2}$ & 0.00 & 0.36 & 32 \\
\hline Harpalus rubripes & 13.31 & $<0.001$ & 11.20 & 0.002 & - & 0.41 & 0.00 & 33 \\
\hline Notiophilus palustris & - & - & 9.20 & 0.005 & $\mathrm{x}, \mathrm{x}^{2}$ & 0.22 & 0.12 & 31 \\
\hline Ophonus azureus & 4.71 & 0.030 & - & - & - & 0.13 & 0.00 & 34 \\
\hline Poecilus versicolor & 23.27 & $<0.001$ & - & - & $\mathrm{x}, \mathrm{y}, \mathrm{x}^{2}, \mathrm{y}^{2}$ & 0.25 & 0.41 & 30 \\
\hline Pterostichus ovoideus & 4.55 & 0.040 & 4.42 & 0.043 & - & 0.21 & 0.00 & 33 \\
\hline Carabids total & 30.65 & $<0.001$ & 9.26 & 0.005 & $\mathrm{x}, \mathrm{y}$ & 0.40 & 0.24 & 31 \\
\hline
\end{tabular}

${ }^{\$} \mathrm{Chi}^{2}$-values and P-values for the final models (GLM-nb) are shown; ${ }^{\dagger}$ proportion of the variability in the data explained by trap design (the construction and preservative used); ${ }^{\S}$ proportion of the variability in the data explained by spatial position of the trap in the grid.

resulted in a total of 36 samples, nine from each particular pitfall trap design.

\section{Total catch and species-specific efficiency}

To assess the effect of trap construction and preservative on the total catch and catch of particular species (number of individuals caught), we employed generalised linear models with negative binomial distribution of errors (GLM-nb; White \& Bennetts, 1996), because of the considerable over-dispersion present in models with a Poisson distribution of errors (Crawley, 2007). We analysed the effects of trap construction, preservative used and their interaction on the number of individuals caught, and the models were controlled for spatial gradients and spatial autocorrelation. This was achieved by using the spatial positions of particular traps as covariates in the models (see below). Species models were developed for the most abundant species in our dataset (more than 10 individuals caught).

In the first step, we selected proper "spatial" covariates for each model. The potential maximal model consisted of the coordinates of the particular trap in the grid, their interaction and second powers $\left(\mathrm{x}, \mathrm{y}, \mathrm{x} \mathrm{y}, \mathrm{x}^{2}, \mathrm{y}^{2}\right)$. Modelling started with a null model followed by a stepwise forward selection based on deletion tests ( $\mathrm{Chi}^{2}$-tests). Covariates selected for particular models are listed in Table 1. In the second step, we searched for a final model, and covariates selected in the first step were used to control for the spatial effects. To select the appropriate final model, stepwise forward selection based on deletion tests (Chi ${ }^{2}$-tests) was used, starting with the null model consisting of spatial covariates. The maximum models may potentially contain covariates, the trap construction, the preservative used and their interaction. Analyses were performed in R version 2.11 ( $\mathrm{R}$ Development Core Team, 2010).

\section{Species richness}

The effect of the trap construction, preservative fluid used and their interaction on species richness of the catches of particular traps was investigated by GLM in a similar way to catch size (see above). However, GLM with Poisson distribution of errors
(GLM-p) was used instead of GLM-nb. One final model was constructed using selected spatial covariates (selected by manual forward selection procedure; see above). Moreover, another final model was constructed using selected spatial covariates and square-root transformed catch as a covariate correcting for variance in sample size between particular traps (as used by Lange et al., 2011). Comparison between these two models enabled us to conclude whether possible difference in species richness recorded by traps of a particular design was a consequence of differences in sample sizes or particular designs of traps caught different numbers of species even if similar numbers of individuals are collected. Analyses were performed in $\mathrm{R}$ version 2.11 ( $\mathrm{R}$ Development Core Team, 2010).

Because total species richness sampled at a particular site (by multiple traps) is frequently used in ecological studies, we also applied individual-based rarefaction with $95 \%$ confidence intervals to investigate differences in species richness among complete assemblages recorded by particular designs of pitfall trap. Individual-based rarefaction allows for the comparison of datasets varying in size via standardisation to the same number of individuals (Gotelli \& Colwell, 2001). Prior to analysis of rarefied species richness, we pooled samples from all nine traps of a particular design to obtain one species assemblage for each trap design. This analysis was performed in $\mathrm{R}$ version 2.11 ( $\mathrm{R}$ Development Core Team, 2010) using package Vegan (Oksanen et al., 2010).

\section{Species composition}

To assess the effects of the construction, the preservation fluid and their interaction on species composition of the catches of particular pitfall traps, we used multidimensional ordination techniques. Direct linear analysis (redundancy analysis, hereafter referred to as RDA) was used because the length of the gradient on the first axis in the detrended correspondence analysis was quite short (as recommended by Lepš \& Šmilauer, 2003). We used significant spatial coordinates (selected by manual forward selection among $\mathrm{x}, \mathrm{y}, \mathrm{x} \mathrm{y}, \mathrm{x}^{2}, \mathrm{y}^{2}$ ) as covariates 


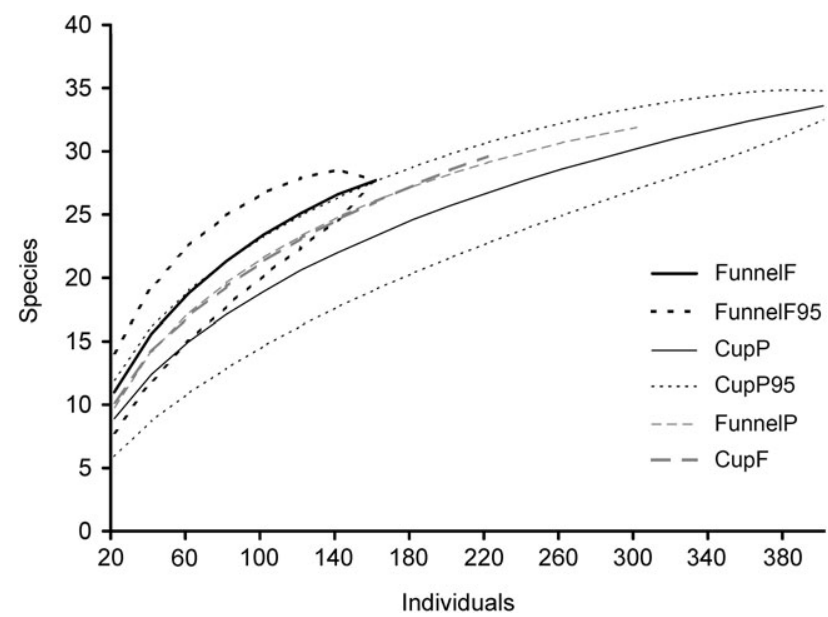

Fig. 2. Rarefaction curves for the assemblages of ground beetles (Coleoptera: Carabidae) caught by pitfall trap of four different designs. Dotted lines indicate $95 \%$ confidence intervals for the two assemblages most unequal in species richness, i.e. those caught by funnel traps filled with formaldehyde and cup traps filled with propylene glycol.

to control for possible spatial environmental gradients and autocorrelation. The species data were logarithmically transformed $\left[\log _{10}(\mathrm{x}+1)\right]$ prior to the analysis. We performed two analyses: (i) no standardization applied in order to record all the variability in species composition attributable to trap construction and preservative used and (ii) the samples were standardised by norm to suppress the effect of different sample sizes. The significance of RDA was assessed by a randomisation test with 999 permutations (Lepš \& Šmilauer, 2003). The analysis was performed in Canoco for Windows version 4.5 (ter Braak \& Smilauer, 2002).

\section{RESULTS}

\section{Total catch and species-specific efficiency}

In total, we collected 1100 specimens of 51 species. There were significant differences in the total number of individuals caught by the differently designed pitfall traps (see total numbers in Appendix). The traps filled with propylene glycol caught significantly more individuals in comparison to those filled with formaldehyde (GLM-nb: $\mathrm{Chi}^{2}=30.65$, d.f. $\left.=1, \mathrm{P}<0.001\right)$. Cup traps caught significantly more individuals than funnel traps (GLM-nb: $\mathrm{Chi}^{2}=9.26$, d.f. $=1, \mathrm{P}=0.005$ ). The position of the traps significantly affected the size of the catch; therefore, spatial coordinates $(\mathrm{x}, \mathrm{y})$ were used as covariates in the final model (Table 1).

In total, 14 species were abundant enough (more than 10 specimens in total) to justify the use of GLM-nb models. The trap construction significantly affected the size of the catches of seven of these 14 species. Carabus nemoralis and Bembidion lampros were caught in higher numbers by the funnel traps, and more Brachinus crepitans, Harpalus latus, Harpalus rubripes, Notiophilus palustris and Pterostichus ovoideus were caught by the cup traps. The preservative used significantly affected the size of the catches of six species (Carabus granulatus, Carabus nemoralis, Harpalus rubripes, Ophonus azureus, Poecilus versicolor and Pterostichus ovoideus), while, for all

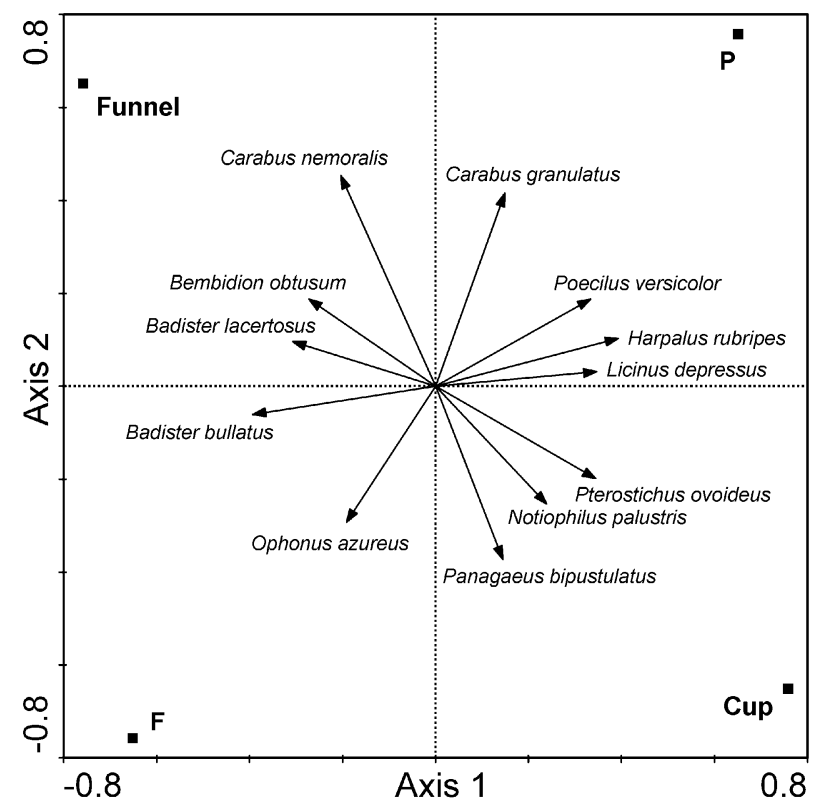

Fig. 3. Ordination diagram (RDA) illustrating the effect of pitfall trap design on species composition of ground beetles (Coleoptera: Carabidae). Samples were standardised by the norm. The effect of trap construction (Cup - cup trap; Funnel funnel trap) and preservative used ( $\mathrm{P}$ - propylene glycol; $\mathrm{F}$ formaldehyde), controlled for spatial autocorrelation, accounted for $11.5 \%$ of the variability in species data (the first canonical axis explained $7.0 \%$; the second canonical axis explained $4.5 \%$; permutation test for all canonical axes: $\mathrm{F}=2.371 ; \mathrm{P}=0.001$ ). Covariates (spatial position of traps) accounted for $16.1 \%$ of the variability in species data.

the significantly affected species, except Ophonus azureus, traps filled with propylene glycol caught more of these beetles than those filled with formaldehyde. Catches of the remaining four species (Amara convexior, Amara lunicollis, Badister bullatus and Harpalus luteicornis) were not affected by trap construction or preservative used. There was no significant interaction between trap construction and preservative used in any of the final models.

\section{Species richness}

Number of species caught by particular traps was significantly affected by the preservative used (GLM-p: Chi ${ }^{2}$ $=4.68$, d.f. $=1, \mathrm{P}=0.031$ ) when no correction for sample size was applied. However, when sample size was incorporated into the analysis as a covariate, the number of species caught was unaffected by the preservative (GLM-p: $\mathrm{Chi}^{2}=0.02$, d.f. $=1, \mathrm{P}=0.88$ ) or trap construction (GLM-p: $\mathrm{Chi}^{2}=0.02$, d.f. $=1, \mathrm{P}=0.89$ ).

There was a nearly significant $(\mathrm{P}=0.05)$ difference between species richness of assemblages when rarefaction was used. Cup traps with propylene glycol caught slightly fewer species than funnel traps with formaldehyde when species richness was rarefied to the same number of specimens (Fig. 2).

\section{Species composition}

Species composition was significantly affected by trap construction and preservative used when logarithmically 
transformed absolute abundances were processed (no standardization by samples applied; permutation test for all canonical axes: $\mathrm{F}=3.941, \mathrm{P}=0.001$ ). Trap construction and preservative used together explained $17.2 \%$ of the variability in species data after correcting for trap position ( $\mathrm{x}, \mathrm{y}$ and $\mathrm{x}^{2}$ were used as covariates according to forward selection).

Species composition was still significantly affected by trap construction and preservative used when data were corrected for differences in the sizes of the samples (standardization by samples was applied; permutation test for all canonical axes: $\mathrm{F}=2.371, \mathrm{P}=0.001$; Fig. 3). Trap construction and preservative used together explained $11.5 \%$ of the variability in species data $\left(x, y\right.$ and $x^{2}$ were used as covariates). The latter analysis reports variability in relative abundance of species in traps of particular designs.

\section{Effect of trap position}

In most analyses, spatial position of the trap had a substantial effect on the analyzed characteristics (catch size, species richness or species composition). Its effect varied with response variable, but in general was comparable to the effect of trap construction (see $\mathrm{R}^{2}$ values in Table 1). Spatial position of the trap explained $17.5 \%$ and $16.1 \%$ of the variability in species composition when RDA without standardization and with standardization by samples, respectively, were employed.

\section{DISCUSSION}

Although pitfall trapping is the most common technique used for sampling epigeal arthropods, samples collected by pitfall traps may be biased in many ways (Greenslade, 1964; Adis, 1979; Topping \& Sunderland, 1992; Southwood, 1994; Spence \& Niemelä, 1994; Hatten et al., 2007; Schirmel et al., 2010). The majority of studies compare pitfall trap designs in the search for the most efficient or most environmentally friendly trap design for monitoring biodiversity (e.g., by catching the fewest vertebrates; Lemieux \& Lindgren, 1999; Work et al., 2002; Buchholz et al., 2010; Lange et al., 2011). In the present study, we focused on the effect of trap design on a wide range of characteristics frequently analysed in ecological studies. Total catch of particular species, species composition and species richness of the assemblages sampled were significantly affected by the pitfall trap design used, however the effect of trap design on species richness vanished when a correction for sample size was applied.

Trap construction (cup or funnel trap) and preservative used (propylene glycol or formaldehyde) significantly affected the total catch, and this result corresponds to previous studies (Lemieux \& Lindgren, 1999; Pekár, 2002; Lange et al., 2011). Based on data in the literature, the following possible mechanisms responsible for the effect of trap construction and preservative on pitfall catches were identified: (i) the trap construction affects the ability of individuals to avoid falling into the trap (e.g., by hanging on to the rim of the trap; Halsall \& Wratten, 1988); (ii) the funnel acts as a mechanical barrier preventing escape from the trap (Obrist \& Duelli, 1996); (iii) various preservatives differ in "attractiveness" for particular species (Pekár, 1996; Weeks \& McIntyre, 1997); and (iv) preservatives differ in the time needed to kill the individuals, and a longer time to death increases the risk of escape (Pekár, 1996). In our study, cups were more efficient (on average they caught higher numbers of carabids) than funnel traps, whereas the opposite pattern is reported by Lange et al. (2011) and Obrist \& Duelli (1996). This difference can be caused by differences in the way we constructed the funnel and that used by Lange at al. (2011) and Obrist \& Duelli (1996). The funnel used in our study contained a "flex point" (funnel was the upper part of a plastic bottle) and such a horizontal segment of funnel could provide beetles with an opportunity to avoid falling into the trap. It is well known that the size of the catch is affected by movement activity, which could be influenced by ambient temperature, hunger level of specimens etc. (Southwood, 1994; Honěk, 1997; Thomas et al., 2006). In addition, our results indicate that the total catch is also affected by trap design. Therefore, comparison of total abundances (activity densities) across studies using various trap design could be misleading.

Catches of particular species were also affected by trap design. The response of the majority of species to trap construction was similar to that of the total catch (higher catches in cup traps), which is not surprising as total catch depends on the sum of the catches of particular species and, in addition, a few abundant species (e.g., Poecilus versicolor, Harpalus latus and Harpalus luteicornis) made up a large part of the catches. Similarly, there were higher catches of most species in traps filled with propylene glycol. However, the traps of different designs caught similar numbers of some species. Finally, other species were caught in higher numbers by the trap of the design or containing the preservative that caught the smallest total catch (e.g., more Carabus nemoralis was caught by funnel traps and Ophonus azureus by traps with formaldehyde solution). It is known that capture rates differ markedly for different species of carabid beetle (Halsall \& Wratten, 1988). Such variability in capture rate seems to be associated with particular behavioural patterns and sensory skills, particularly the speciesspecific ability to perceive the edge of a trap (Halsall \& Wratten, 1988). The capture rate may vary even between closely related species (e.g., Poecilus versicolor and Poecilus cupreus) (Mommertz et al., 1996). Moreover, Pekár (1996) reports that the capture rate for particular species is different depending on the preservative used. Differences in capture rates (catches) of traps of different designs of particular species recorded in this study are therefore a consequence of interactions between trap design and behaviour of particular species.

The variation in species-specific capture rates of particular designs of trap may lead to substantial differences in the recorded species composition of a community, depending on the trap design used. Assemblages sampled by a particular trap design consisted of similar species (the 13 most numerous species were caught by both the trap designs tested; see Appendix). Nevertheless, 
recorded species composition was significantly affected by trap construction and preservative used. This pattern remained unchanged even after application of the correction for unequal sample size (standardization by samples). Our results thus indicate that different pitfall trap designs are able to catch similar species, but their relative abundances in traps of a particular design differ significantly. Such a bias might be substantial in studies investigating fine-scale effects on species assemblages, where phenomenon under study might be obscured by the effect of trap design.

Our finding of a rather small effect of pitfall trap design on the number of species of carabid caught agrees with the results of Lange et al. (2011). In contrast, Weeks \& McIntyre (1997) observed differences in species richness of arthropods caught by pitfall traps depending on the preservative used; however, in their study, species richness was not corrected for variation in sample size. As total catch usually varies significantly among different trap designs (see results; Luff, 1975; Lemieux \& Lindgren, 1999; Pekár, 2002; Work et al., 2002; Buchholz et al., 2010), correcting for unequal sample size is crucial. Species richness in our experiment was significantly affected by the preservative fluid used when we did not correct for unequal sample size, but this result vanished after correction for unequal sample size. This correction is therefore necessary for meaningful comparison of ground beetle species richness sampled by pitfall traps of different designs.

The spatial component in catch size, species richness and species composition recorded in this study could have been caused by gradients in environmental characteristics (e.g. humidity or vegetation cover), which we did not measure and therefore could not include in the analyses. The study area was adjacent to a more humid area of fallow land in the east and this could have affected some species. Interestingly, several species were more abundant in traps in the central part of the grid, which probably caused the non-linear effects $\left(\mathrm{x}^{2}\right.$ and $\left.\mathrm{y}^{2}\right)$. This pattern contradicts the "depletion hypothesis" discussed by Digweed et al. (1995) and indicates that $12 \mathrm{~m}$ spacing is sufficient to avoid depletion effects when sampling for a short period of time.

In conclusion, our results indicate that the total catch, catch of particular species and species composition can be substantially affected by trap design. If the variability (bias) in the data introduced by trap design is comparable to that generated by the phenomenon under study, the results might be misleading. Therefore, experiments simultaneously comparing the performance of traps of several designs in an ecological study are greatly needed if sound conclusions are to be drawn about the suitability of pitfall trapping. In addition to methodological benefits, simultaneous use of traps of several different designs may provide more complex information on the assemblage of epigeal arthropods.

ACKNOWLEDGEMENTS. The study was financially supported by grants CIGA \#20084201 and IGA \#42110/1312/3124 awarded by the Czech University of Life Sciences Prague. We are grateful to J. Knappová, P. Saska (both Praha, Czech Republic) and two anonymous reviewers for their valuable comments on previous versions of this manuscript and to P. Moravec (Litoměřice, Czech Republic) for confirmation our carabid beetle identifications.

\section{REFERENCES}

Absolon K., Benda P., Chrudina Z., Klaudisova A., Paril P. \& RicaneK M. 1994: Methodology of Data Collection for Biomonitoring in Protected Areas. Český ústav ochrany prrírody, Praha, 70 pp. [in Czech].

ADIs J. 1979: Problems of interpreting arthropod sampling with pitfall traps. Zool. Anz. 202: 177-184.

ARneberg P. \& Andersen J. 2003: The energetic equivalence rule rejected because of a potentially common sampling error: evidence from carabid beetles. Oikos 101: 367-375.

Buchiolz S., Jess A.M., Hertenstein F. \& Schirmel J. 2010: Effect of the colour of pitfall traps on their capture efficiency of carabid beetles (Coleoptera: Carabidae), spiders (Araneae) and other arthropods. Eur. J. Entomol. 107: 277-280.

Crawley M.J. 2007: The R Book. Wiley, Chichester, 950 pp.

Digmeed S.C., Currie C.R., Carcamo H.A. \& Spence J.R. 1995: Digging out the "digging-in effect" of pitfall traps: Influences depletion and disturbance on catches of ground beetles (Coleoptera: Carabidae). Pedobiologia 39: 561-576.

ELPHICK C.S. 2008: How you count counts: the importance of methods research in applied ecology. J. Appl. Ecol. 45: $1313-1320$

Gotelli N.J. \& Colwell R.K. 2001: Quantifying biodiversity: procedures and pitfalls in the measurement and comparison of species richness. Ecol. Lett. 4: 379-391.

Greenslade P.J.M. 1964: Pitfall trapping as a method for studying populations of carabidae (Coleoptera). J. Anim. Ecol. 33: 301-310.

Halsall N.B. \& Wratten S.D. 1988: The efficiency of pitfall trapping for polyphagous predatory Carabidae. Ecol. Entomol. 13: 293-299.

Hatten T.D., Bosque-Perez N.A. \& Johnson-Maynard J. 2007: Tillage differentially affects the capture rate of pitfall traps for three species of carabid beetles. Entomol. Exp. Appl. 124: 177-187.

HoNĚK A. 1988: The effect of crop density and microclimate on pitfall trap catches of Carabidae, Staphylinidae (Coleoptera), and Lycosidae (Araneae) in cereal fields. Pedobiologia 32: 233-242.

HoNĚK A. 1997: The effect of temperature on the activity of Carabidae (Coleoptera) in a fallow field. Eur. J. Entomol. 94: 97-104.

HůRKA A. 1996: Carabidae of the Czech and Slovak Republics. Kabourek, Zlín, 565 pp.

Lange M., Gossner M.M. \& WeIsser W.W. 2011: Effect of pitfall trap type and diameter on vertebrate by-catches and ground beetle (Coleoptera: Carabidae) and spider (Araneae) sampling. Method. Ecol. Evol. 2: 185-190.

LEMIEUX J.P. \& LindGREN B.S. 1999: A pitfall trap for largescale trapping of Carabidae: Comparison against conventional design, using two different preservatives. Pedobiologia 43: 245-253.

LePš J. \& Šmilauer P. 2003: Multivariate Analysis of Ecological Data Using CANOCO. Cambridge University Press, Cambridge, $269 \mathrm{pp}$.

LuFF M.L. 1975: Some features influencing efficiency of pitfall traps. Oecologia 19: 345-357.

Mommertz S., Schauer C., Kosters N., Lang A. \& Filser J. 1996: A comparison of D-Vac suction, fenced and unfenced 
pitfall trap sampling of epigeal arthropods in agroecosystems. Ann. Zool. Fenn. 33: 117-124.

Obrist M.K. \& Duelli P. 1996: Trapping efficiency of funneland cup-traps for epigeal arthropods. Mitt. Schw. Entomol. Ges. 69: 361-369.

Oksanen J., Blanchet F.G., Kindt R., Legendre P., O'Hara R.B., Simpson G.L., Solymos P., Stevens M.H.H. \& Wagner H. 2010: Vegan: Community Ecology Package. Version 1.17-10. Available at http://vegan.r-forge.r-project.org/

PeKÁR S. 1996: A laboratory study of the efficiency and attractiveness of pitfall traps for Pardosa agrestis (Aranea). Acta Soc. Zool. Bohem. 60: 191-197.

PeKÁr S. 2002: Differential effects of formaldehyde concentration and detergent on the catching efficiency of surface active arthropods by pitfall traps. Pedobiologia 46: 539-547.

R Development Core Team 2010: A Language and Environment for Statistical Computing. Available at http://www. R-project.org

Schirmel J., Lenze S., Katzmann D. \& Buchiolz S. 2010: Capture efficiency of pitfall traps is highly affected by sampling interval. Entomol. Exp. Appl. 136: 206-210.

Southwood T.R.E. 1994: Ecological Methods: With Particular Reference to the Study of Insect Populations. Chapman \& Hall, London, $524 \mathrm{pp}$.

SPENCE J.R. \& Niemelä J.K. 1994: Sampling carabid assemblages with pitfall traps - the madness and the method. Can. Entomol. 126: 881-894.
Ter Braak C.J.F. \& Šmilauer P. 2002: CANOCO Reference Manual and CanoDraw for Windows User's Guide: Software for Canonical Community Ordination (version 4.5). Microcomputer Power, Ithaca, NY, 500 pp.

Thomas C.F.G., Brown N.J. \& Kendall D.A. 2006: Carabid movement and vegetation density: Implications for interpreting pitfall trap data from split-field trials. Agr. Ecosyst. Environ. 113: 51-61.

Topping C.J. \& SunDERLAND K.D. 1992: Limitations to the use of pitfall traps in ecological-studies exemplified by a study of spiders in a field of winter-wheat. J. Appl. Ecol. 29: 485-491.

Tropek R., Kadlec T., Karesova P., Spitzer L., Kocarek P., Malenovsky I., Banar P., Tuf I.H., Hejda M. \& Konvicka M. 2010: Spontaneous succession in limestone quarries as an effective restoration tool for endangered arthropods and plants. J. Appl. Ecol. 47: 139-147.

WeEKs R.D. \& MCINTYRe N.E. 1997: A comparison of live versus kill pitfall trapping techniques using various killing agents. Entomol. Exp. Appl. 82: 267-273.

White G.C. \& BenNetTs R.E. 1996: Analysis of frequency count data using the negative binomial distribution. Ecology 77 : 2549-2557.

Work T.T., Buddle C.M., Korinus L.M. \& Spence J.R. 2002: Pitfall trap size and capture of three taxa of litter-dwelling arthropods: Implications for biodiversity studies. Environ. Entomol. 31: 438-448.

Received September 21, 2011; revised and accepted May 19, 2012 
APPENDIX. Numbers of ground beetles (Coleoptera: Carabidae) caught by pitfall traps of a particular design and containing a particular preservative.

\begin{tabular}{|c|c|c|c|c|c|}
\hline & Funnel $^{1}+\mathrm{F}^{2}$ & Cup + F & Funnel $+\mathrm{P}$ & Cup + P & In total \\
\hline Poecilus versicolor (Sturm, 1824) & 18 & 43 & 101 & 131 & 293 \\
\hline Harpalus latus (Linnaeus, 1758) & 20 & 36 & 24 & 43 & 123 \\
\hline Harpalus luteicornis (Duftschmid, 1812) & 23 & 27 & 33 & 32 & 115 \\
\hline Harpalus rubripes (Duftschmid, 1812) & 8 & 18 & 20 & 48 & 94 \\
\hline Pterostichus ovoideus (Sturm, 1824) & 6 & 17 & 17 & 35 & 75 \\
\hline Brachinus crepitans (Linnaeus, 1758) & 3 & 18 & 8 & 41 & 70 \\
\hline Badister bullatus (Schrank, 1798) & 20 & 17 & 11 & 14 & 62 \\
\hline Carabus nemoralis O. F. Müller, 1764 & 8 & 3 & 24 & 5 & 40 \\
\hline Ophonus azureus (Fabricius, 1775) & 17 & 9 & 2 & 6 & 34 \\
\hline Carabus granulatus Linnaeus, 1758 & 1 & 2 & 11 & 6 & 20 \\
\hline Notiophilus palustris (Duftschmid, 1812) & 1 & 6 & 1 & 7 & 15 \\
\hline Bembidion lampros (Herbst, 1784) & 4 & 1 & 7 & 1 & 13 \\
\hline Amara lunicollis Schiödte, 1837 & 5 & 2 & 3 & 2 & 12 \\
\hline Amara convexior Stephens, 1828 & 2 & 0 & 2 & 7 & 11 \\
\hline Microlestes minutulus (Goeze, 1777) & 0 & 3 & 3 & 4 & 10 \\
\hline Anchomenus dorsalis (Pontoppidan, 1763) & 0 & 3 & 4 & 2 & 9 \\
\hline Amara montivaga Sturm, 1825 & 1 & 2 & 3 & 3 & 9 \\
\hline Stomis pumicatus (Panzer, 1796) & 2 & 1 & 4 & 1 & 8 \\
\hline Pterostichus melanarius (Illiger, 1798) & 1 & 0 & 3 & 3 & 7 \\
\hline Panagaeus bipustulatus (Fabricius, 1775) & 0 & 4 & 0 & 2 & 6 \\
\hline Bembidion obtusum Audinet-Serville, 1821 & 2 & 1 & 3 & 0 & 6 \\
\hline Harpalus tardus (Panzer, 1797) & 0 & 3 & 0 & 2 & 5 \\
\hline Amara ovata (Fabricius, 1792) & 0 & 3 & 1 & 1 & 5 \\
\hline Amara plebeja (Gyllenhal, 1810) & 4 & 0 & 0 & 1 & 5 \\
\hline Amara aenea (De Geer, 1774) & 1 & 0 & 3 & 0 & 4 \\
\hline Syntomus truncatellus (Linnaeus, 1761) & 0 & 1 & 0 & 3 & 4 \\
\hline Clivina fossor (Linnaeus, 1758) & 0 & 1 & 3 & 0 & 4 \\
\hline Microlestes maurus (Sturm, 1827) & 2 & 0 & 1 & 1 & 4 \\
\hline Badister lacertosus Sturm, 1815 & 2 & 0 & 1 & 0 & 3 \\
\hline Amara familiaris (Duftschmid, 1812) & 1 & 1 & 0 & 1 & 3 \\
\hline Amara bifrons (Gyllenhal, 1810) & 0 & 0 & 2 & 1 & 3 \\
\hline Ophonus rufibarbis (Fabricius, 1792) & 1 & 0 & 0 & 2 & 3 \\
\hline Carabus convexus Fabricius, 1775 & 0 & 1 & 1 & 0 & 2 \\
\hline Molops elalatus (Fabricius, 1801) & 1 & 0 & 0 & 1 & 2 \\
\hline Licinus depressus (Paykull, 1790) & 0 & 0 & 0 & 2 & 2 \\
\hline Harpalus affinis (Schrank, 1781) & 0 & 1 & 0 & 1 & 2 \\
\hline Amara communis (Panzer, 1797) & 2 & 0 & 0 & 0 & 2 \\
\hline Pterostichus vernalis (Panzer, 1796) & 0 & 0 & 2 & 0 & 2 \\
\hline Pterostichus niger (Schaller, 1783) & 0 & 1 & 0 & 0 & 1 \\
\hline Cicindela campestris Linnaeus, 1758 & 1 & 0 & 0 & 0 & 1 \\
\hline Bembidion properans (Stephens, 1828) & 0 & 0 & 0 & 1 & 1 \\
\hline Abax parallelepipedus (Piller et Mitterpacher, 1783) & 0 & 0 & 1 & 0 & 1 \\
\hline Harpalus atratus Latreille, 1804 & 0 & 1 & 0 & 0 & 1 \\
\hline Amara similata (Gyllenhal, 1810) & 0 & 0 & 0 & 1 & 1 \\
\hline Amara aulica (Panzer, 1797) & 0 & 0 & 0 & 1 & 1 \\
\hline Abax parallelus (Duftschmid, 1812) & 0 & 1 & 0 & 0 & 1 \\
\hline Pterostichus melas (Creutzer, 1799) & 0 & 0 & 1 & 0 & 1 \\
\hline Leistus ferrugineus (Linnaeus, 1758) & 0 & 0 & 1 & 0 & 1 \\
\hline Badister sodalis (Duftschmid, 1812) & 1 & 0 & 0 & 0 & 1 \\
\hline Ophonus melleti (Heer, 1837) & 0 & 1 & 0 & 0 & 1 \\
\hline Brachinus explodens Duftschmid, 1812 & 0 & 0 & 1 & 0 & 1 \\
\hline In total individuals & 158 & 228 & 302 & 412 & 1100 \\
\hline In total species & 28 & 30 & 32 & 34 & 51 \\
\hline
\end{tabular}

\footnotetext{
${ }^{1}$ trap construction (funnel - funnel trap; cup - trap made of a plastic cup); ${ }^{2}$ preservative used ( $\mathrm{F}$ - formaldehyde; $\mathrm{P}-$ propylene
} glycol). 